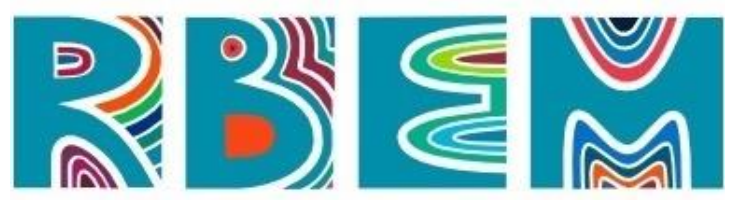

REVISTA BAIANA DE EDUCAÇÃO MATEMÁtICA

$\underline{\text { ARTIGO }}$

do] https://doi.org/10.47207/rbem.v1i.10256

\title{
Desenvolvimento do pensamento aritmético de um estudante com deficiência intelectual: uma investigação utilizando o Tampimática
}

\author{
MILLI, Elcio Pasolini \\ Secretaria Estadual de Educação do Espírito Santo (Sedu-ES). Mestre em Educação em Ciências e Matemática \\ pelo Instituto Federal do Espírito Santo (Ifes). \\ ORCID: https://orcid.org/0000-0002-6459-6291. E-mail: elciopmilli@gmail.com.
}

THIENGO, Edmar Re is

Instituto Federal do Espírito Santo (Ifes). Doutor em Educação pela Universidade Federal do Espírito Santo (Ufes). Professor do Programa de Pós-Graduação em Educação em Ciências e Matemática (EDUCIMAT/Ifes). ORCID: https://orcid.org/0000-0002-4423-4939. E-mail: thiengo@ifes.edu.br.

Resumo: Este artigo apresenta um recorte de uma pesquisa de mestrado em Educação em Ciências e Matemática realizada com um estudante com deficiência intelectual do Programa Nacional de Integração da Educação Profissional com a Educação Básica na Modalidade de Educação de Jovens e Adultos (Proeja). O objetivo foi analisar o desenvolvimento do pensamento aritmético de um aluno com deficiência intelectual, particularmente a apropriação da quantificação e da representação numérica, utilizando o Tampimática. Trata-se de uma investigação fundamentada no método funcional da estimulação dupla desenvolvido por Vigotski, aliado à observação livre discutida por Triviños. Discute as potencialidades da pessoa com deficiência intelectual de acordo com o desenvolvimento cognitivo, no que tange às possibilidades de emancipação do sujeito numa perspectiva dialógica, desenvolvido a partir dos processos de mediação. Aponta discussões sobre o pensamento aritmético, caracterizando as relações entre as construções de novos signos por meio da educação matemática crítica, trabalhada numa perspectiva inclusiva. Contém observações e experiências vivenciadas na prática pedagógica junto ao Proeja, explorando o Tampimática, ao trabalhar a quantificação e a representação numérica. Destaca-se nesta investigação a contribuição da mediação e as relações sociais nos processos compensatórios para superação das dificuldades relacionadas à deficiência intelectual. Em relação ao aluno participante desta pesquisa, consideramos que os meios auxiliares, como a fala, os gestos, as atividades escritas e os objetos que contribuíram no processo de compensação para o desenvolvimento do pensamento aritmético. Assim, discutimos a educação matemática inclusiva como forma a superar nossas dificuldades e desenvolver novas potencialidades, colaborando no processo de transformação educacional.

Palavras-chave: Deficiência intelectual. Pensamento Aritmético. Tampimática. Proeja.

\section{Development of arithmetic thinking in a student with intellectual disabilities: an investigation using Tampimática}

\begin{abstract}
This paper presents an excerpt from a master's research in Science and Mathematics Education carried out with a student with intellectual disability from the Programa Nacional de Integração da Educação Profissional com a Educação Básica na Modalidade de Educação de Jovens e Adultos (Proeja). The objective was to analyze the development of the arithmetic thinking of a student with intellectual disabilities, particularly the appropriation of quantification and numerical
\end{abstract}




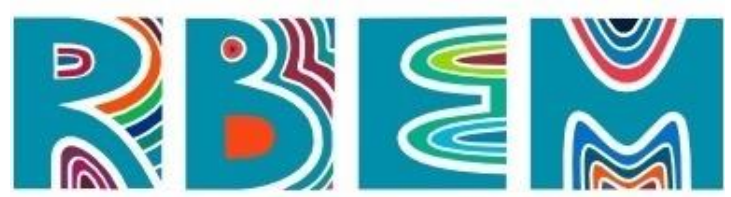

REVISTA BAIANA DE EDUCAÇÃO MATEMÁtICA

representation, using Tampimática. It is an investigation based on the functional method of double stimulation developed by Vigotski, combined with the free observation discussed by Triviños. It discusses the potential of the person with intellectual disability according to the cognitive development, regarding the possibilities of emancipation of the subject in a dialogical perspective, developed from the mediation processes. It points out discussions about arithmetic thinking, characterizing the relationships between the construction of new signs through critical mathematical education, worked from an inclusive perspective. It contains observations and experiences lived in the pedagogical practice with Proeja, exploring Tampimática, when working with quantification and numerical representation. In this investigation, the contribution of mediation and social relations in the compensatory processes to overcome difficulties related to intellectual disability is highlighted. Regarding the student participating in this research, we consider that the auxiliary means, such as speech, gestures, written activities and objects, contributed to the compensation process for the development of arithmetic thinking. Thus, we discussed inclusive mathematical education as a way to overcome our difficulties and develop new potential, collaborating in the process of educational transformation.

Keywords: Intellectual Disability. Arithmetic Thinking. Tampimática. Proeja.

\section{Desarrollo del pensamiento aritmético de un estudiante con discapacidad intelectual: una investigación usando Tampimática}

Resumen: Este artículo presenta un extracto de una investigación de maestría en Educación en Ciencias y Matemáticas realizada con un estudiante con discapacidad intelectual del Programa Nacional de Integração da Educação Profissional com a Educação Básica na Modalidade de Educação de Jovens e Adultos (Proeja). El objetivo fue analizar el desarrollo del pensamiento aritmético de un estudiante con discapacidad intelectual, particularmente la apropiación de la cuantificación y la representación numérica, utilizando Tampimática. Es una investigación basada en el método funcional de doble estimulación desarrollado por Vigotski, combinado con la observación libre discutida por Triviños. Discute el potencial de la persona con discapacidad intelectual de acuerdo con el desarrollo cognitivo, con respecto a las posibilidades de emancipación del sujeto en una perspectiva dialógica, desarrollada a partir de los procesos de mediación. Señala discusiones sobre el pensamiento aritmético, que caracteriza las relaciones entre la construcción de nuevos signos a través de la educación matemática crítica, trabajado desde una perspectiva inclusiva. Contiene observaciones y experiencias vividas en la práctica pedagógica con Proeja, explorando Tampimática, cuando se trabaja con cuantificación y representación numérica. En esta investigación, se destaca la contribución de la mediación y las relaciones sociales en los procesos compensatorios para superar las dificultades relacionadas con la discapacidad intelectual. Con respecto al estudiante que participa en esta investigación, consideramos que los medios auxiliares, como el habla, los gestos, las actividades escritas y los objetos, contribuyeron al proceso de compensación por el desarrollo del pensamiento aritmético. Así, discutimos la educación matemática inclusiva como una forma de superar nuestras dificultades y desarrollar un nuevo potencial, colaborando en el proceso de transformación educativa.

Palavras-Clave: Discapacidad Intelectual. Pensamiento Aritmético. Tampimática. Proeja. 


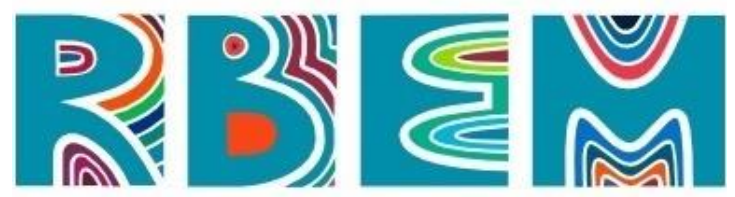

REVISTA BAIANA dE EDUCAÇÃo MATEMÁtICA

\section{Introdução}

Discutir educação matemática inclusiva é pensar nas possibilidades de aprendizagem de todos os envolvidos no processo educacional. É preciso pensar a educação matemática como oportunidade de desenvolvimento de práticas e estudos que promovam a inclusão de todos em tom de equidade. No entanto, alguns grupos menos favorecidos no cenário educacional também precisam desse olhar inclusivo. Destacamos as questões étnico-raciais, religiosas, sociais, culturais, dificuldades de aprendizagem, opção sexual, identidade de gênero, idade escolar, educação especial, entre tantos outros aspectos existentes na sociedade e, portanto, nas salas de aula. Desse modo, mais do que questões, estamos falando de pessoas envolvidas no processo educacional.

Nesta perspectiva, o relatório técnico do Censo Escolar da Escola Básica, realizado no ano de 2018, pelo Instituto Nacional de Estudos e Pesquisas Educacionais Anísio Teixeira Inep, aponta que "O número de matrículas da educação especial chegou a 1,2 milhão em 2018, um aumento de 33,2\% em relação a 2014. Esse aumento foi influenciado pelas matrículas de ensino médio que dobraram durante o período" (BRASIL, 2019, p. 4), fato que valoriza as pesquisas neste campo no cenário educacional brasileiro.

Ao considerar essa demanda, apresentamos um recorte de uma pesquisa de mestrado profissional em Educação em Ciências e Matemática, denominada Desenvolvimento do Pensamento Aritmético de um Estudante com Deficiência Intelectual na Educação de Jovens e Adultos (MILLI, 2019). O objetivo neste texto foi analisar o desenvolvimento do pensamento aritmético, particularmente a apropriação da representação numérica e da quantificação, de um aluno com deficiência intelectual do Programa Nacional de Integração da Educação Profissional com a Educação Básica na Modalidade de Educação de Jovens e Adultos (Proeja) ao utilizar o Tampimática (MILLI; THIENGO, 2019), produto educacional elaborado durante a realização desta pesquisa de mestrado profissional, conforme apresentado na Figura 1. 

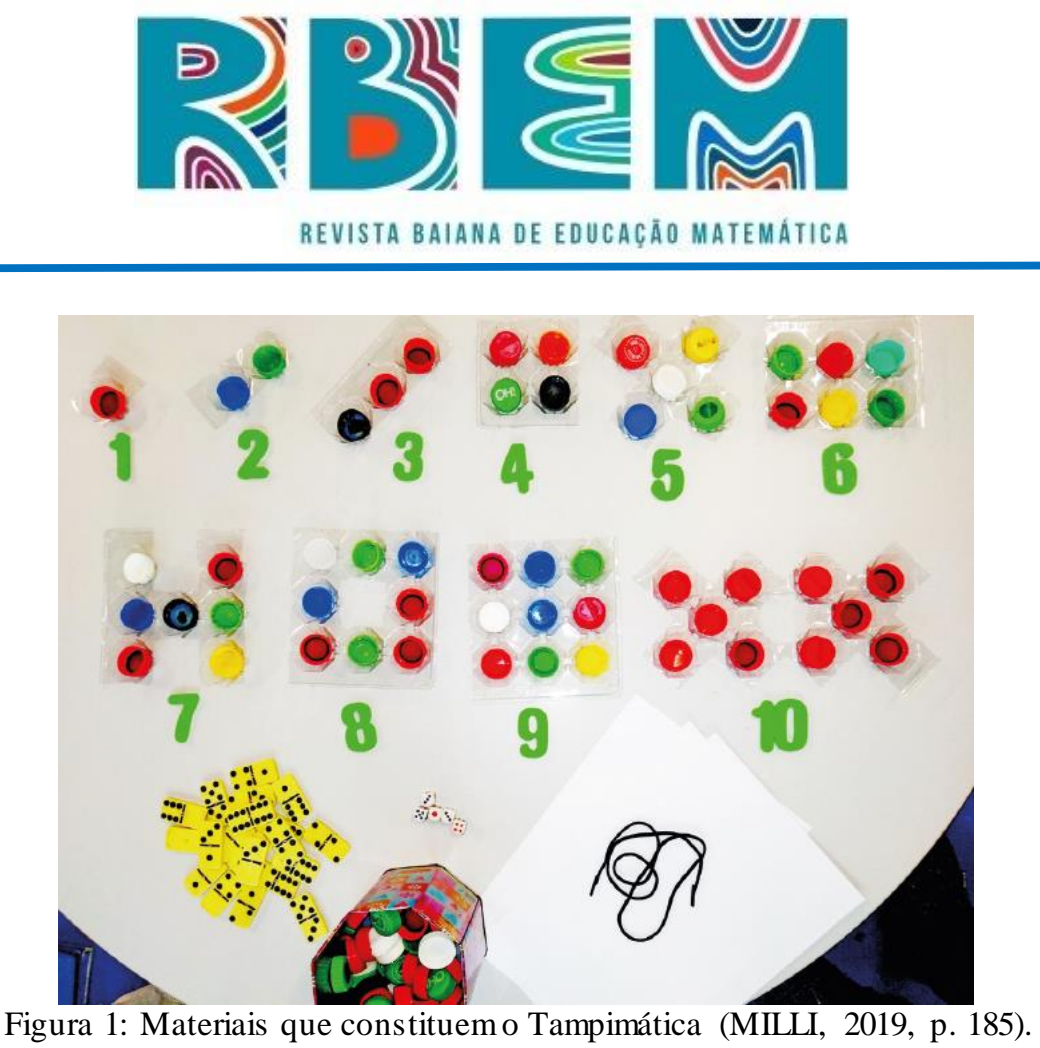

O Tampimática é um material manipulável constituído por uma coleção de tampinhas e acessórios que auxiliam as práticas de manipulação durante as atividades, como barbantes, embalagens de ovos (estruturas), folhas de papel e fichas numéricas, que associados a dados e dominós buscam atender os objetivos pedagógicos propostos pelas atividades matemáticas. Assim, essa atividade foi realizada por meio da associação de um material concreto manipulável junto às mediações realizadas pelo pesquisador. Investigamos o campo

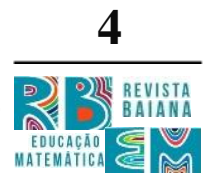
aritmético, tendo em vista o desenvolvimento do conceito de número, através da quantificação e dos registros em diálogos e imagens, para compreender o desenvolvimento do pensamento aritmético do aluno com deficiência intelectual.

\section{Fundamentação Teórica}

O Estatuto da Pessoa com Deficiência, instituído pela Lei Brasileira de Inclusão da Pessoa com Deficiência, em seu art. $2^{\circ}$, preconiza:

Considera-se pessoa com deficiência aquela que tem impedimento de longo prazo de natureza física, mental, intelectual ou sensorial, o qual, em interação com uma ou mais barreiras, pode obstruir sua participação plena e efetiva na sociedade em igualdade de condições com as demais pessoas (BRASIL, 2015, s. p.).

Entretanto, neste estudo, considera-se também que cada indivíduo apresenta suas particularidades, principalmente, relacionadas à aprendizagem, independentemente de ter ou 


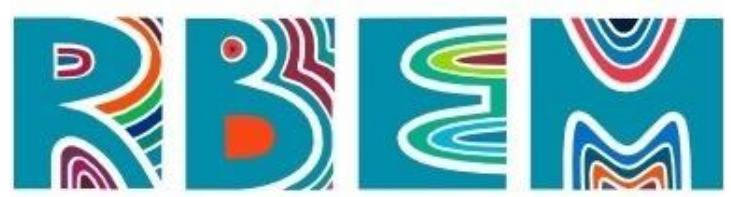

REVISTA BAIANA dE EDUCAÇÃo MATEMÁtICA

não deficiência. Nesse sentido, a escola tem fundamental importância e responsabilidade de trabalhar para superar ${ }^{1}$ as diversas barreiras, devendo propiciar ambientes de interação social com acesso à educação em uma condição de equidade, para que todos possam apreender.

Em estudos realizados sobre aprendizagem, mediação e interação social, Vigotski (1997) discute a aprendizagem e o desenvolvimento humano de crianças com deficiência em suas investigações sobre a defectologia. Para ele, a deficiência não impossibilita a aprendizagem, mas cria, por meio de mecanismos compensatórios, novas possibilidades.

[...] todo defeito cria estímulos para elaborar uma compensação. Por isso o estudo dinâmico da criança deficiente não pode limitar-se a determinar o nível e gravidade da insuficiência, mas sim incluir obrigatoriamente a consideração dos processos compensatórios, e escolher substitutos reestruturados e niveladores para o desenvolvimento e a conduta da criança (VIGOTSKI, 1997, p. 14).

Assim, visando desenvolver um trabalho que favorecesse a superação de obstáculos advindos da deficiência, a fim de contribuir para o desenvolvimento da educação matemática, nos direcionamos para o campo do pensamento aritmético. Ao falar em pensamento aritmético nos referimos a um espaço do pensamento matemático, relacionado ao número e às

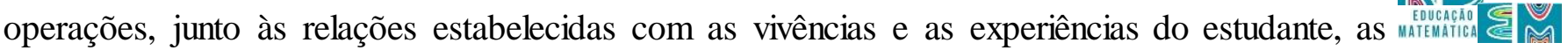
quais propiciam processos de ensino e aprendizagem por meio das interações sociais. Segundo Portanova (2005)

[...] a capacidade de raciocínio de um aluno desenvolve-se ao longo de um período de tempo e está intimamente ligada à vivência de uma gama de experiências variadas e potencialmente ricas, relacionadas aos diferentes tipos de pensamentos que estão inter-relacionados aos diferentes ramos da matemática: a lógica, a aritmética, a álgebra, a geometria, a probabilidade e a estatística, e que devem ser, especialmente no ensino fundamental, apresentados como um todo integrado, num currículo em espiral, organizado num grau crescente de complexidade (PORTANOVA, 2005, p. 19).

Esse fato valoriza as discussões que prezam pelo diálogo entre os saberes escolares e os saberes cotidianos. Isso não caracteriza um distanciamento de conhecimentos, mas são experiências que precisam ser alinhadas para que, quando forem debatidas, possam produzir sentido na vida desse aluno. Nesse caminho, tomamos as experiências que favorecessem o

\footnotetext{
1 A noção de superação em Vigotski (1997) está associada à ideia de transpor, ou até mesmo de contornar um obstáculo, não afirmando o desaparecimento deste. Pelo contrário, a superação só acontece pela existência de um obstáculo, fato es encial para compreender o conceito de compens ação.
} 


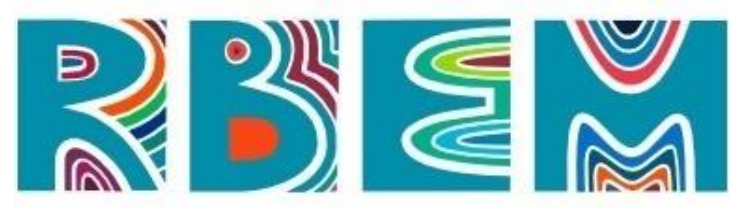

REVISTA BAIANA dE EDUCAÇÃo MATEMÁtICA

aprimoramento do pensamento aritmético. A proposta foi, então, desenvolver atividades que valorizassem a experimentação do raciocínio lógico, do desenvolvimento do sentido numérico, da capacidade de estimativa e do cálculo mental. Essas atividades, aliadas ao campo aritmético, dialogam com a produção de signos estimuladores da produção de conceitos científicos.

A escola é, sim, lugar de tematizações. De formalizações, esse é papel importante que ela deve cumprir. $\mathrm{O}$ de introduzir as crianças em sistemas de significados o que Vigotski chamou de conceitos científicos, e que correspondem a um corpo de noções sistematizadas (LINS; GIMENEZ, 1997, p. 23).

É preciso pensar na produção de conhecimentos de forma crítica e não simplesmente produzir resultados sem interpretação e justificativa para os valores encontrados. É importante destacar que produzir "um sentido estrutural operativo dos números é muito mais do que saber calcular muitos resultados, ou pretender saber o porquê deles" (LINS; GIMENEZ, 1997, p. 73).

Desse modo, o desafio é realizar um trabalho relacionando o pensamento aritmético à educação crítica. Assim, para promover uma educação matemática crítica que permita utilizar

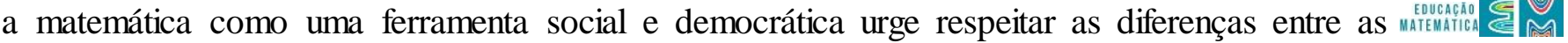
concepções já impregnadas que constituem o próprio ser. Freire (1996) alerta sobre a necessidade de romper com o autoritarismo na busca de entender o outro.

Aceitar e respeitar a diferença é uma dessas virtudes sem o que a escuta não se pode dar. Se discrimino o menino ou menina pobre, a menina ou o menino negro, o menino índio, a menina rica; se discrimino a mulher, a camponesa, a operária, não posso falar com eles, mas a eles, de cima para baixo. Sobretudo me proíbo entendê-los. Se me sinto superior ao diferente, não importa quem seja, recuso-me escutá-lo ou escutá-la. O diferente não é o outro a merecer respeito é um isto ou aquilo, destratável ou desprezível (FREIRE, 1996, p. 120-121).

Para isso, o educador que busca a liberdade de seus alunos deve se direcionar para a construção de uma educação crítica pautada na ética, no respeito e no desenvolvimento da autonomia desses sujeitos. Skovsmose (2001) corrobora nesse sentido e orienta a desenvolver um conhecer reflexivo.

Como parte de nossa cultura, estruturada pela tecnologia, uma competência no reconhecer e interpretar a matemática como uma atividade social e instituição torna-se importante. Especialmente: o conhecer reflexivo tem de 


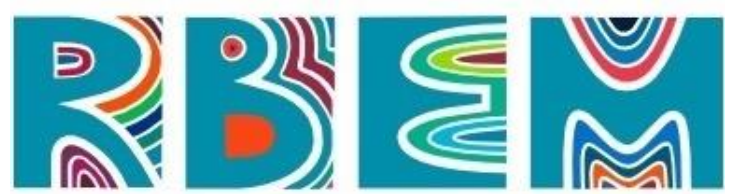

REVISTA BAIANA DE EDUCAÇÃO MATEMÁtICA

ser desenvolvido para dar à alfabetização matemática uma dimensão crítica (SKOVSMOSE, 2001, p. 118).

O autor ainda destaca a importância de construir uma educação matemática crítica que propicie relações sociais entre professores e alunos, a fim de intervir na relação democrática. Nesse sentido, o estudo desenvolvido teve o propósito de associar o desenvolvimento do pensamento aritmético a uma educação matemática crítica, valorizando o desenvolvimento crítico e autônomo dos estudantes, principalmente, daqueles marginalizados devido à injustiça social. Nessa perspectiva, o autor propõe utilizar a educação matemática crítica para fazer uma leitura e escrita de mundo de forma reflexiva em alguns grupos específicos de estudantes, dos quais nos interessa aqueles com deficiência e/ou alunos da EJA.

\section{Aspectos Metodológicos}

A investigação foi trabalhada de forma que os processos cognitivos do aluno participante pudessem ser compreendidos por meio da valorização da interação social, principalmente, os relacionados ao desenvolvimento dos processos psicológicos superiores, destacando-se o pensamento abstrato, a memória lógica, a fala e a escrita. Também são relevantes os recursos semióticos reflexivos voltados para a produção de signos emergentes da linguagem escrita e falada, da expressão gestual, da elaboração de registros pictóricos e da manipulação de objetos concretos. Para tanto, foi utilizado o método desenvolvido por Vigotski (1998) denominado método funcional da estimulação dupla, aliado à observação livre proposta por Triviños (2017). Os dados da pesquisa foram produzidos e registrados em anotações de campo de natureza descritiva e reflexiva, com base nas atividades pedagógicas propostas e em diálogos com o aluno participante.

Para Vigotski (1998), um experimento deveria oferecer diferentes estímulos e oportunidades para que o participante da pesquisa pudesse experimentar variadas atividades, a fim de constituir de diferentes formas o desenvolvimento intelectual.

Ao usar essa abordagem, não nos limitamos ao método usual que oferece ao sujeito estímulos simples dos quais se espera uma resposta direta. Mais do que isso, oferecemos simultaneamente uma segunda série de estímulos que têm função especial. Dessa maneira, podemos estudar o processo de realização de uma tarefa com ajuda de meios auxiliares específicos; assim, também seremos capazes de descobrir a estrutura interna e o 


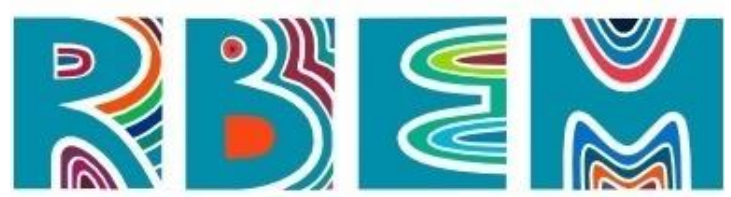

REVISTA BAIANA DE EDUCAÇÃO MATEMÁTICA

desenvolvimento dos processos psicológicos superiores (VIGOTSKI, 1998, p. 98).

Com base nesses estímulos o indivíduo cria seus signos para realizar a atividade proposta. O problema é apresentado desde o início do processo, o que possibilita ao participante acompanhar todo o desenvolvimento da atividade e do raciocínio, sem focar apenas no resultado final. As mediações acontecem durante o processo, permitindo realizar intervenções para que o sujeito possa se apropriar de novos signos, principalmente, os relacionados ao desenvolvimento intelectual.

Aliado ao método pedagógico de Vigotski (1998) foi utilizada uma metodologia de pesquisa cuja finalidade foi registrar a produção de dados por meio da observação livre. Entendemos que observar não se trata de um ato simples de olhar. Observar exige destacar um conjunto de características específicas de um grupo e distanciá-lo de seu contexto, produzindo uma conjectura em sua dimensão singular e também interconectar suas relações e aspectos interacionais para captar suas representações em um contexto pluralista. Assim, a observação livre, satisfaz os princípios da pesquisa qualitativa ao destacar a importância do participante na investigação, apontando categorias a partir da apropriação dos conceitos pelo aluno, durante o processo de análise de dados.

A observação livre, ao contrário da observação padronizada, satisfaz as necessidades principais da pesquisa qualitativa, como, por exemplo, a relevância do sujeito, neste caso, da prática manifesta do mesmo e ausência total ou parcial, de estabelecimento de pré-categorias para compreender o fenômeno que se observa (TRIVIÑOS, 2017, p.153-154).

A observação livre colabora com o método funcional da estimulação dupla, pois permite que as produções de signos oferecidos nos estímulos duplamente qualificados sejam observadas e categorizadas conforme a apropriação do participante em sua estrutura interna. Ao propor uma atividade pedagógica, também surge outro estímulo por meio de um objeto neutro, que pode ser utilizado pelo participante como um novo signo, desse modo, contribuindo para solucioná-la. Nesse momento as ações do aluno são mediadas pelo professor e, portanto, também por meio de diálogos, que permitem observar o que está sendo produzido no aparato cognitivo para realizar a tarefa, valorizando o que o estudante está pensando durante a execução das tarefas e não apenas o resultado final.

Convém ressaltar que esta pesquisa foi aprovada pelo Comitê de Ética em Pesquisa do 


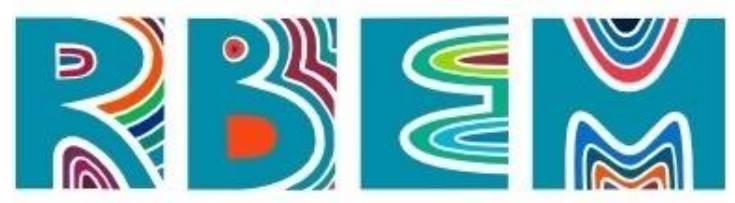

REVISTA BAIANA DE EDUCAÇÃO MATEMÁtICA

Instituto Federal do Espírito Santo - CEP/Ifes, a qual está vinculada esta investigação por meio do Programa de Pós-Graduação em Educação em Ciências e Matemática - Educimat. Está registrada no Parecer $\mathrm{n}^{\mathrm{o}}$ 2.804.024 referente ao Certificado de Apresentação para Apreciação Ética - CAAE - número 91117018.9.0000.5072. Vale ressaltar que a pesquisa foi conduzida de acordo com os padrões éticos exigidos transcorrendo da forma menos invasiva possível em relação às singularidades e particularidades dos envolvidos, sem exposição e identificação de seus colaboradores, sempre com assentimento livre e esclarecido.

\section{Descrição e Análise dos Dados}

Os estudos direcionados ao desenvolvimento do pensamento aritmético nos apontam as aprendizagens relacionadas ao sentido numérico. Lins e Gimenez (1997, p. 160) consideram que a "Educação aritmética precisa ampliar o conjunto de habilidades e atividades que considera - com vistas sempre no desenvolvimento do sentido numérico". Um dos caminhos representativos no desenvolvimento do conceito de número está associado à ideia de quantidade.

Por exemplo, ao pensar no número 5, associamos uma quantidade de elementos de um conjunto em que é feita uma correspondência termo a termo, o qual é definido com base em uma sequência ordenada, o número cinco. Essas ideias associadas ao conceito do número vão além da associação de número como quantidades.

Por isso, neste artigo apresentamos um recorte das atividades com base nas observações feitas em sala de aula durante aulas de matemática de uma pesquisa de mestrado profissional. Semanalmente, o pesquisador acompanhou as aulas em que o aluno participante da pesquisa estudava, tendo como princípio identificar as experiências matemáticas já conhecidas por ele. Trata-se de um aluno, que na época tinha 63 anos de idade, com deficiência intelectual, decorrente de anoxia (oxigenação cerebral insuficiente) durante o parto, que cursava o terceiro semestre do curso Guia de Turismo ofertado na modalidade presencial por meio do Proeja. Essa atividade foi desenvolvida em parceria com o Atendimento Educacional Especializado (AEE), no contra turno, e com o Grupo de Pesquisa em Educação, História e Diversidades (Gpehdi), do qual os autores participam. 


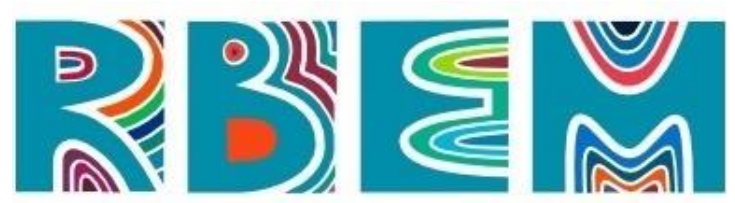

REVISTA BAIANA DE EDUCAÇÃO MATEMÁtICA

Primeiramente, buscamos entender quais estratégias de quantificação o aluno utilizava e se ele compreendia a conservação de quantidades em determinados conjuntos. Iniciando a atividade, colocamos 13 tampinhas de mesma cor sobre a mesa, próximas umas das outras, e perguntamos quantas tampinhas ele achava que tinha sobre a mesa, solicitando que fizesse uma estimativa. O aluno olhou, pensou um pouco e respondeu: “Umas dez!”, e logo em seguida perguntou se poderia contar. Após a confirmação do pesquisador o aluno iniciou a contagem, contando elemento por elemento, separando-os do grupo inicial, a fim de não repetir a contagem do mesmo elemento e respondeu ao final que havia treze tampinhas naquele grupo.

A estimativa torna-se um importante passo no desenvolvimento do pensamento aritmético. "Se nos é apresentado um conjunto de pontinhos ou uma foto de uma manifestação, por exemplo, e não nos é dado muito tempo para contar, ficamos abrigados a desenvolver habilidades de estimativa que não são próprias de um pensamento absoluto, mas relativo” (LINS E GIMENEZ, 1997, p. 50).

Observamos que para "estimar" a quantidade de tampinhas o aluno teve dificuldades ao refletir sobre qual número falaria. Essa atividade não é comumente desenvolvida em sala de aula para a quantificação, sendo mais valorizado o processo de contagem, tanto que o aluno a realizou imediatamente após a estimativa. Mesmo que o número 10 seja uma boa estimativa para o número 13, a insatisfação com o resultado aponta uma necessidade de fazer a contagem baseada em nosso background, principalmente sobre nossas experiências matemáticas vivenciadas. É com ele que se criam as expectativas para construir o foreground, sobre as expectativas e desejos de aprendizagem (SKOVSMOSE, 2017). Desse modo, ao pensar em ações socializadoras e comunicativas, é preciso pensar em uma atividade que comungue de uma proposta dialógica entre professor e aluno, já que "o processo educacional deve ser entendido como um diálogo" (SKOVSMOSE, 2001, p. 18).

A estimativa permite adquirir certa noção sobre a quantidade de elementos, porém não trabalha com a quantidade exata de elementos de um conjunto discreto. Esse fato não minimiza a estratégia utilizada pelo aluno, pelo contrário, valoriza a construção do sentido numérico. Torna-se um momento introdutório para trabalhar a quantificação associada com a noção de número, já que o aluno, logo em seguida, perguntou se poderia contar a quantidade de elementos. 


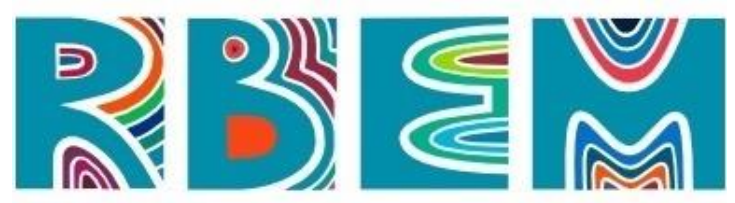

REVISTA BAIANA DE EDUCAÇÃO MATEMÁtICA

Ao continuar com a atividade o pesquisador pegou as mesmas tampinhas e as distribuiu sobre a mesa de forma espaçada, perguntando ao aluno quantas tampinhas havia sobre a mesa. O aluno respondeu treze, sem efetuar uma nova contagem. Em seguida, o pesquisador as colocou enfileiradas, uma ao lado da outra, e perguntou novamente quantas tampinhas havia ali, e o aluno respondeu novamente treze. E o pesquisador continuou:

Pesquis ador: "Se eu fizer assim, têm quantas tampinhas aqui?";

Aluno: "Eu vou fechar o olho e nem vou contar nada!";

Pesquisador: "Ok, tudo bem! Pode responder direto. Quantas tampinhas têm aqui?";

Aluno: "Treze!";

Pesquisador: "E se eu fizer assim com elas, quantas tampinhas têm aqui?", espalhando elas sobre a mesa.

Aluno: "Juntar isso aqui tudinho?", apontando para as tampinhas sobre a mesa.

Pesquis ador: "É, quero saber quantas tampinhas tenho aqui.";

Aluno: "Tem treze também!";

Pesquis ador: "Por quê? Eu coloquei alguma tampinha?";

Aluno: "Não!";

Pesquis ador: "Eu tirei alguma tampinha?";

Aluno: "Não! É tipo um conjunto de tampinhas!";

Pesquisador: "É um conjunto de tampinhas! Então, se eu juntar as tampinhas ou se eu colocar elas espalhadas, a quantidade muda?";

Balançando a cabeça e mostrando que não, o aluno disse: "É a mesma coisa!” (MILLI, 2019, p. 186).

Após a sequência de perguntas feitas pelo pesquisador e as respostas do aluno, este não fez mais a contagem dos elementos do conjunto e afirmou, com certeza, a quantidade de tampinhas apresentada no conjunto. Esse fato pode ser verificado em algumas falas, "Eu vou fechar o olho e nem vou contar nada!", e “É a mesma coisa!”. Essas falas permitem entender o que aluno pensa sobre o material e como conceitua a quantificação baseada na contagem.

Portanova (2005) destaca a importância de construir noções de conservação e inclusão para desenvolver o conceito de número. A não conservação de elementos de um conjunto pode ser considerada uma dificuldade para entender a quantificação, uma vez que a disposição dos elementos, tamanhos e formas pode se tornar um obstáculo ao desenvolvimento da noção de número, tornando-se uma barreira no desenvolvimento do pensamento aritmético. No entanto, esse fato não foi notado no desenvolvimento matemático do aluno e, mais precisamente, no campo da aritmética. Acreditamos que esta atividade permitiu conhecer um pouco mais do aluno quanto suas concepções numéricas. 


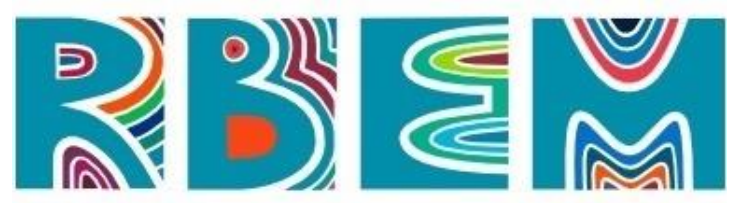

REVISTA BAIANA DE EDUCAÇÃO MATEMÁTICA

Por isso, ao prosseguir com a atividade, as mesmas treze tampinhas foram colocadas enfileiradas e o aluno deveria separar três tampinhas daquele grupo. Sem contar, o aluno colocou a mão em três tampinhas e as separou do grupo. Em seguida, o pesquisador pediu cinco tampinhas, e o aluno as contou e separou. O pesquisador colocou-as novamente na posição de fileira e pediu ao aluno para selecionar dez tampinhas, e ele contou dez tampinhas e as entregou na mão do pesquisador.

Observamos nesse momento que o aluno não teve dificuldade para quantificar os elementos com base em um conjunto definido previamente. Notamos que diferentes estratégias de quantificação foram adotadas para separar as quantidades três e cinco. Ao selecionar a quantidade cinco, o aluno associou a cada elemento do conjunto um número de uma sequência numérica ordenada e finalizou ao chegar ao elemento solicitado, no caso cinco. O que ocorreu diferentemente na quantificação de três elementos, em que o aluno selecionou as tampinhas apenas ao olhar para elas e tocá-las com a mão. Na primeira maneira de quantificar destaca-se a contagem. Já na segunda, destaca-se o subitizing. Para Clements (1999. p. 1), subitizing significa "visualizar uma quantidade instantaneamente" e deriva da palavra "subitamente". Portanto, subitizing é a capacidade de quantificar um conjunto discreto subitamente, sem utilizar um processo de contagem. Por isso, é preciso destacar a importância de refletir sobre diferentes formas de entender a quantificação e, consequentemente, o conceito de número. Clements (1999) conclui que o subitizing é uma importante habilidade matemática que possibilita compreender melhor o conceito de número, pois trabalha ideias de conservação e compensação, que dialoga com a composição e decomposição de números na construção do sistema de numeração decimal, ampliando o desenvolvimento do pensamento aritmético (PORTANOVA, 2005).

Em seguida, o pesquisador colocou sete tampinhas alinhadas sobre a mesa e estipulou uma ordem para a sequência de tampinhas em primeira, segunda, terceira, até a sétima tampinha, e solicitou que o aluno separasse três tampinhas. Ele colocou três dedos, um em cada tampinha e separou três tampinhas. Posteriormente, o pesquisador solicitou que o aluno identificasse a terceira tampinha da sequência. Ele apontou, então, para a terceira tampinha, separando-a do grupo. "Como já sabido, até três a percepção da contagem é imediata; mais do que três requer algum processamento da informação visual” (LINS e GIMENEZ, 1997, p. $50)$. 


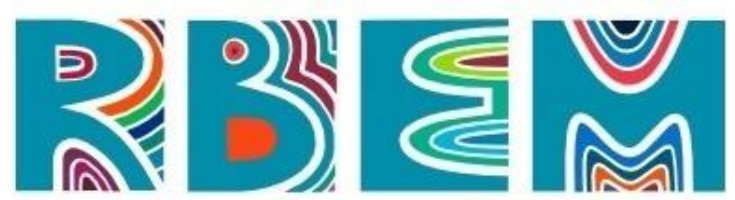

REVISTA BAIANA DE EDUCAÇÃO MATEMÁtICA

Essa observação foi importante para entender como o aluno compreendeu a construção numérica durante outras atividades. Destacamos, por exemplo, as diferentes construções e representações referentes ao número 12 durante a realização de outras atividades, como o registro pictórico da multiplicação $3 \times 4$, a representação com algarismos indo-arábicos, a associação elemento-algarismo, a quantificação de 12 tampinhas num espaço delimitado, o preenchimento da estrutura com 12 cavidades e, sobretudo a conexão entre essas diferentes representações, físicas e mentais, conforme apresentado na Figura 2.

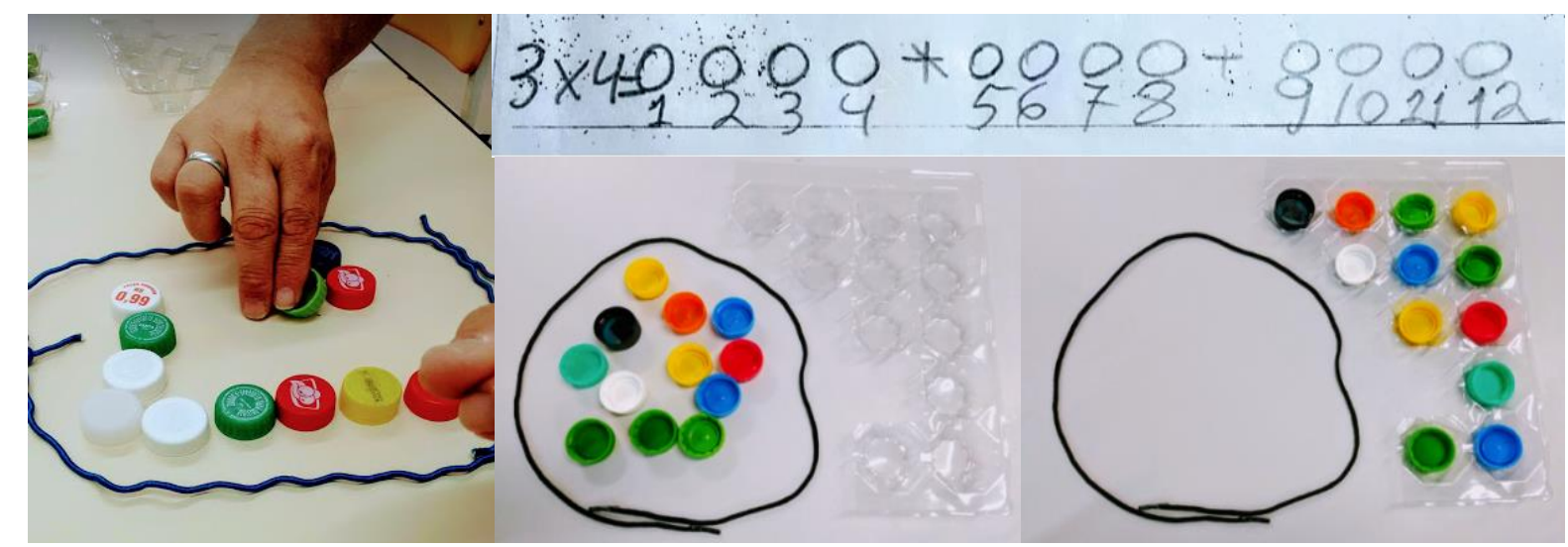

Figura 2: Representações da construção numérica referente ao número 12 (MILLI, 2019, p. 84).

O fato de ter escrito um numeral abaixo de cada símbolo icônico, em sequência de 1 a 12, consolida-se como uma estratégia de contagem em que cada numeral, elemento a elemento, é associado a um único símbolo desenhado. A associação unívoca é utilizada para verificar até qual elemento da sequência numérica um, dois, três... deve ser associado às "bolinhas" para serem contadas. Para o aluno, a quantidade doze foi representada pelo conjunto de todos os elementos desenhados e não apenas para o décimo segundo elemento da sequência desenhada, confirmando algumas hipóteses da pesquisa.

Esse fato é reforçado por Portanova (2005, p. 19) quando aponta a necessidade de "Relacionar dois conjuntos unívoca ou biunivocamente" com aplicação de "Atividades com jogos e materiais concretos". A utilização do Tampimática possibilitou realizar a contagem com base na relação elemento (tampinha) e representação aritmética (número). Além disso, permitiu entender que a associação dos numerais com os desenhos da Figura 2 foi uma estratégia de correspondência biunívoca na quantificação, apontando para o sentido numérico e para o desenvolvimento do pensamento aritmético. 


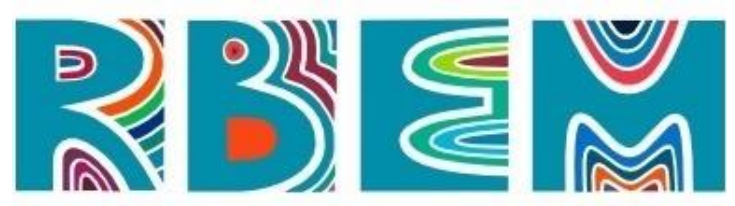

REVISTA BAIANA dE EDUCAÇÃO MATEMÁtICA

$\mathrm{O}$ ato de contar coopera com o desenvolvimento do pensamento aritmético, como a contagem dos elementos pictóricos feita pelo aluno, a contagem das tampinhas e também a multiplicação 3x4. Portanova (2005, p. 20) destaca como um dos pontos para desenvolver o pensamento aritmético "O alcance da noção de quantidade como uma totalidade composta por unidade, que permanece constante através das variações, decomposições, distribuições". Assim, por meio dos registros icônicos, da quantificação das tampinhas e dos registros escritos podemos compreender como o aluno conceitua com a quantidade doze.

A partir destas experiências durante a investigação e as estratégias adotadas pelo aluno em parceria com o pesquisador, o trabalho foi ampliado para os conceitos de número e suas representações por meio da utilização de novos objetos, como as tampinhas. "A aritmética tem trazido diversas contribuições à história e à cultura como: a quantificação e o desenvolvimento de sistemas de agrupamento" (LINS E GIMENEZ, 1997, p. 39). Essa experiência foi acrescentada às oportunidades vivenciadas pelo aluno em sala de aula para implementar sua expectativa com essas experiências históricas e culturais relacionadas à quantificação e, nesse sentido, reestruturar o foreground dele (SKOVSMOSE, 2006).

Nesse sentido, observamos que a fala é uma estrutura superior importante para permitir que o aluno apresente, por meio da mediação, a progressão de seu pensamento aritmético. O desenvolvimento do pensamento aritmético desse estudante também não aconteceu de forma pontual. De acordo com o apresentado nesta pesquisa, o raciocínio do aluno articulou-se de forma dinâmica com as aprendizagens já adquiridas, que permitem constante reorganização e desenvolvimento do pensamento aritmético, tendo em vista as novas considerações ponderadas pelo aluno durante a realização das tarefas.

É relevante destacar que os processos compensatórios influenciam a aprendizagem de conceitos da aritmética para um estudante com deficiência intelectual de maneira particular. Notamos que experiências matemáticas oriundas das relações sociais permitem que os processos compensatórios contribuam para superar as dificuldades relacionadas à deficiência.

Em relação ao aluno participante desta pesquisa, os meios auxiliares, como a fala, os gestos, as atividades escritas e os objetos foram grandes parceiros no processo de compensação para desenvolver o pensamento aritmético. Os dados apontam que o aluno se apropriou dos estímulos externos originados do pesquisador e das tarefas, quando the foi oferecido oportunidade de realizar uma atividade escrita, ou utilizar comandos gestuais ou 


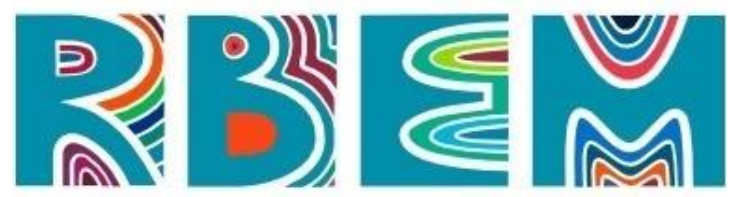

REVISTA BAIANA DE EDUCAÇÃO MATEMÁtICA

ainda perguntas reflexivas acompanhadas de material concreto, como o Tampimática. Porém, de forma análoga, o aluno criou seus próprios estímulos ao ouvir a própria fala por meio da repetição de palavras, pela utilização dos dedos das mãos ao usar o tato e a visão privilegiada em seu campo visual, bem como a escrita, por meio da qual registrou de forma organizada por si mesmo as construções simbólicas de seu pensamento.

\section{Considerações Finais}

Ao analisar a apropriação da representação numérica e da quantificação por um aluno com deficiência intelectual da Educação de Jovens e Adultos percebemos que todos nós aprendemos em contato com o outro. $\mathrm{Na}$ troca de ideias construímos diferentes possibilidades metodológicas de ensino, que propiciam novas estratégias de aprendizagem.

É relevante destacar que os processos compensatórios influenciam a aprendizagem de conceitos da aritmética para um estudante com deficiência intelectual de maneira particular. Notamos que experiências matemáticas oriundas das relações sociais permitem que os processos compensatórios contribuam para superar as dificuldades relacionadas à deficiência. Os meios auxiliares, como a fala, os gestos, as atividades escritas e os objetos cooperaram com processo de compensação para desenvolver o pensamento aritmético.

Nesta pesquisa, consideramos que esse aluno desenvolveu o pensamento aritmético de forma particular, com estratégias próprias e que as relações sociais permitem essa diversidade na produção educacional. Esta pesquisa não esgota as possibilidades investigativas sobre deficiência intelectual ou pensamento aritmético, tampouco sobre o desenvolvimento do pensamento aritmético de um aluno com deficiência intelectual. Mas apontam caminhos que podem ser trilhados ou, pelo menos, algumas direções no processo educacional, motivando provocações e reflexões sobre práticas docentes.

Todos nós temos peculiaridades e, por meio das relações sociais, construímos nossa identidade. Com a pessoa com deficiência intelectual não é diferente. Cada pessoa traz consigo características e especificidades que são um pouco mais exclusivas de si mesmas, não permitindo generalizações, como acontece com outros públicos da educação especial. É preciso tomar cuidado para que nossas particularidades não nos inferiorizem e a igualdade não ofusque nossa identidade. 


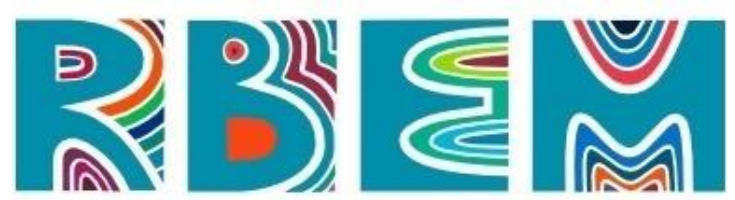

REVISTA BAIANA DE EDUCAÇÃO MATEMÁtICA

\section{Referências}

BRASIL. Secretaria de Educação Básica. Censo escolar da educação básica 2018: resumo técnico / Instituto Nacional de Estudos e Pesquisas Educacionais Anísio Teixeira. - Brasilia: O Instituto, 2019.

BRASIL. Lei no . 13146/15. Lei brasileira de inclusão da pessoa com deficiência - estatuto da pessoa com deficiência. Brasilia: SEF, 2015.

CLEMENTS, Douglas H. (1999). Subtizing: What is it? Why teach it?. Printed from Teaching Children Mathematics and with permission from NCTM, 1999.

FREIRE, Paulo. Pedagogia da autonomia: saberes necessários à prática educativa. São Paulo: Paz e Terra, 1996.

LINS, Romulo Campos; GIMENEZ, Joaquim. Perspectivas em aritmética e álgebra para o século XXI. Campinas: Papirus, 1997.

MILLI, Elcio Pasolini. Desenvolvimento do pensamento aritmético de um estudante com deficiência intelectual na educação de jovens e adultos. 2019. 213 f. Dissertação (Mestrado em Educação em Ciências e Matemática) - Instituto Federal do Espírito Santo - Ifes. Vitória, $2019 . \quad$ Disponível

<https://sucupira.capes.gov.br/sucupira/public/consultas/coleta/trabalhoConclusao/viewTrabal hoConclusao.jsf?popup=true\&id_trabalho=7742319 >. Acesso em: 29 julho 2020.

em:

MILLI, Elcio Pasolini; THIENGO, Edmar Reis. Tampimática: Tampinhas para ensinar matemática. Vitória: Editora Ifes , 2019. Disponível em: $<$ https://educapes.capes.gov.br/bitstream/capes/564301/2/MPCM_\%20Produto\%20Educacion al_\%20E-

book_ELCIO\%20PASOLINI\%20MILLI_Turma\%202017_\%20V\%20FINAL_10.01.2019.pd f >. Acesso em: 29 julho 2020.

PORTANOVA, Ruth (org.). Um currículo de matemática em movimento. Porto Alegre: EDIPUCRS, 2005.

SKOVSMOSE, Ole. O que poderia significar a educação matemática crítica para diferentes grupos de estudantes? Revista Paranaense de Educação Matemática. v.6, n.12, p.18-37, jul.dez. 2017.

SKOVSMOSE, Ole. Educação matemática crítica: A questão da democracia. 5. ed. Campinas, São Paulo: Papirus, 2001.

TRIVIÑOS, Augusto Nibaldo Silva. Introdução à pesquisa em ciências sociais: a pesquisa qualitativa em educação. São Paulo: Atlas, 2017. 


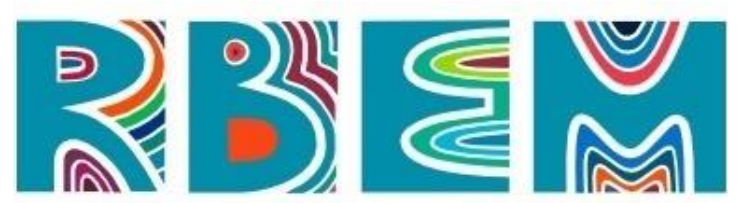

VIGOTSKI, Lev Semionovich. Aprendizagem e desenvolvimento intelectual na idade escolar. In: VIGOTSKI, Lev Semionovich. Linguagem, desenvolvimento e aprendizagem. São Paulo: 2001, p. 103-117.

VIGOTSKI, Lev Semionovich. A formação social da mente: o desenvolvimento dos processos psicológicos superiores. 7. ed. São Paulo: Martins Fontes, 1998.

VIGOTSKI, Lev Semionovich. Fundamentos de defectologia. In: Obras completas. Tomo V. Trad. de Maria del Carmen Ponce Fernandez. Havana: Editorial Pueblo y Educación, 1997. p. 74-87.

YOKOYAMA, Leo Akio. Uma abordagem multissensorial para o desenvolvimento do conceito de número natural em indivíduos com síndrome de Down. 2012. 230 f. Tese (Doutorado em Educação Matemática) - Universidade Bandeirante de São Paulo. São Paulo, 2012.

Disponível

em:

$<$ http//www.matematicainclusiva.net.br/pdf/uma_abordagem_multissensorial_para_o_desenv olvimento_do_conceito_de_numero.pdf >. Acesso em: 29 julho 2020.

Artigo submetido em: 12/11/2020 